\title{
Application of a self-compacting ultra-high-performance fibre-reinforced concrete to retrofit RC beams subjected to repeated loading
}

\author{
B S AL-AZZAWI and B L KARIHALOO* \\ School of Engineering, Cardiff University, Cardiff CF24 3AA, UK \\ e-mail: KarihalooB@Cardiff.ac.uk
}

MS received 30 May 2017; revised 8 September 2017; accepted 26 September 2017; published online 24 July 2018

\begin{abstract}
The aim of this paper is to describe the performance of reinforced concrete (RC) beams retrofitted with a self-compacting ultra-high-performance fibre-reinforced concrete (UHPFRC) under three-point bend cyclic loading. It is found that retrofitting the RC beams with a thin UHPFRC strip on the tension face increases their endurance limit under a non-zero mean stress cyclic loading from approximately $40 \%$ to approximately $60 \%$ of their static three-point flexural strength. Moreover, the retrofitted beams behave as a composite structure, with no delamination of the retrofit strip being observed in any of the fatigue tests.
\end{abstract}

Keywords. UHPFRC; self-compacting mix; flexural fatigue; static flexural strength; fatigue endurance limit; retrofitting.

\section{Introduction}

RILEM 1984 [1] states that fatigue occurs in concrete due to the deterioration of the bond between the coarse aggregate and cement paste with the reduction of the section of the specimen. Alternatively, it happens, simultaneously with the aforementioned one, due to the formation and diffusion of micro-cracks in the cement paste until macrocracks weaken the section and cannot withstand the applied load.

The strengthening of reinforced concrete (RC) structures is, and will continue to be, a relevant problem to accommodate for a load carrying capacity higher than the original design value. In the last decades, rapid progress has been made in the development of strengthening materials and technologies [2].

The earliest method used to strengthen concrete structure is by bonding steel plates to its surface. This method is simple to execute and results in only small changes in the size of the strengthened structure, but it has several drawbacks [3]. Among these are, for example the corrosion of steel, deterioration of the bond at the glued steel-concrete interface, difficulty in the installation of heavy steel plates and limitations in supplying steel plates of required length.

In a later method, fibre-reinforced plastic (FRP) plates have been used. Extensive investigations have been performed using this technique [4-7]. In contrast with the steel plates, the FRP has high strength to weight ratio, good

*For correspondence chemical resistance and is easy to handle, thus reducing the labour costs $[8,9]$. However, long exposure to temperature variations and sunlight can weaken the bond between the FRP composite and concrete [10, 11]. Furthermore, it has been shown that hybridisation with two different fibre types in normal cement matrix produces superior mechanical performance than a single fibre type [12,13].

Another promising material that can be used to enhance the fatigue strength of $\mathrm{RC}$ is the ultra-high-performance fibre-reinforced concrete (UHPFRC). It has relatively high compressive strength, high tensile strength, strain-hardening behaviour under tensile stress (given a certain volume of fibres) and very low permeability because of the use of an optimised dense matrix. Therefore, these properties make UHPFRC suitable for strengthening structural members subjected to severe mechanical and environmental actions [14, 15].

Contemporary line of research for repairing or strengthening concrete members is in the use of cement-based materials. Within this class, a new retrofitting material has been developed at Cardiff University [16-18]. It includes two main groups of UHPFRC mixes - Mixes I and II differing primarily in the maximum size of quartz sand used $(0.6 \mathrm{~mm}$ in Mix I, and $2 \mathrm{~mm}$ in Mix II). The main advantage of this material is its compatibility with concrete. It overcomes some of the problems [19] identified earlier for steel plates and FRP composites, which are primarily due to the mismatch of their tensile strength, stiffness and coefficient of linear thermal expansion with the parent concrete being retrofitted. 
Several studies have previously been undertaken at Cardiff on the feasibility of using this material for the rehabilitation and strengthening of damaged RC flexural members [19-24]. This material is however not cost-competitive because of the use of expensive brass-coated thin steel fibres.

A self-compacting and industrially competitive version of type Mix II, called simply UHPFRC, has been recently developed. Its mechanical and fracture properties (i.e., sizeindependent fracture energy and the corresponding bi-linear stress-crack opening relationship) have been measured and reported in [25] and its flexural fatigue performance in [26].

The aim of this work is to investigate the performance of $\mathrm{RC}$ beams retrofitted with this UHPFRC under three-point bend cyclic loading. This will allow judging the potential of this material for retrofitting purposes.

\section{Control beams}

\subsection{Mixing and casting}

A standard concrete mix (cement:fine aggregate:coarse aggregate:water in the ratio 1:1.8:2.8:0.5) was used. The proportions of materials used are summarised in table 1.

The Portland cement used was Type II Class $42.5 \mathrm{~N}$. The fine aggregate used was dried and sand sieved to remove any large pieces of shell or gravel. The coarse aggregate (crushed limestone) had a maximum size of $10 \mathrm{~mm}$.

Table 1. Material proportions.

\begin{tabular}{lc}
\hline Constituents & Mass $\left(\mathrm{kg} / \mathrm{m}^{3}\right)$ \\
\hline Cement & 394 \\
Fine aggregate & 709.3 \\
Coarse aggregate & 1103.4 \\
Water & 196.61 \\
w/c & 0.5 \\
\hline
\end{tabular}

Due to the extensive use of this mix in the laboratory, no fresh tests were performed on this mix, but the previously reported values [27] of the compressive strength and the split tensile strength (53.5 and 4.4 MPa, respectively) were adopted.

A standard $2500 \mathrm{~mm}$ beam mould was used to cast two shorter $(1200 \mathrm{~mm})$ beams simultaneously with a crosssection of $100 \mathrm{~mm}$ width by $150 \mathrm{~mm}$ depth using a spacer block (figure 1).

The mould was suitably prepared, the spacer block was inserted and the reinforcing bar $(\varphi 12 \mathrm{~mm})$ for each of the two beams was placed (with a cover of $26 \mathrm{~mm}$ from the bar centre to the tension face) on wooden support plates. To prevent leakage, the mould sides were tightened and any gaps were filled with a sealant. Fresh concrete was poured in layers using scoops, and to ensure adequate compaction and removal of entrapped air a poker vibrator was used. The top face was finished with a plasterer's float. The beams were removed from the mould after 1 day and water cured at ambient temperature $\left(20^{\circ} \mathrm{C}\right)$ for 28 days.

\subsection{Three-point static flexural test of control RC beam}

A control RC beam (designated B1) was tested under threepoint loading over a span of $1000 \mathrm{~mm}$, taking care that the test beam was aligned as symmetrically as possible in the testing machine relative to the central load and supports. The rate of loading was $0.01 \mathrm{~mm} / \mathrm{s}$ at the beginning of the test; it was increased to $0.02 \mathrm{~mm} / \mathrm{s}$ after passing the maximum load. The central deflection was measured using a single LVDT placed at its mid-span. Figure 2 shows the load-central deflection response of the control beam. When the load exceeded $5.5 \mathrm{kN}$, the stiffness of the beam decreased but no cracks or damage was observed with a naked eye at this stage. As the load was increased, hairline cracks appeared on the tension face of the beam near the mid-span and at a quarter span from the support. Under further loading, these cracks diffused to the sides of the beam and began to grow towards the compressive zone.

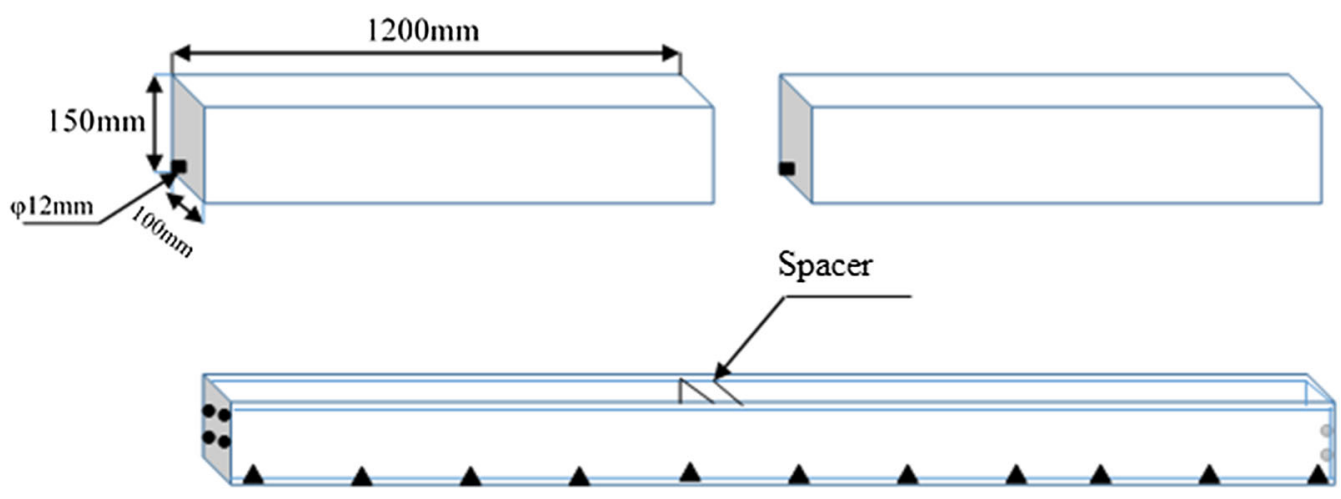

Figure 1. Steel mould for casting two beams. 


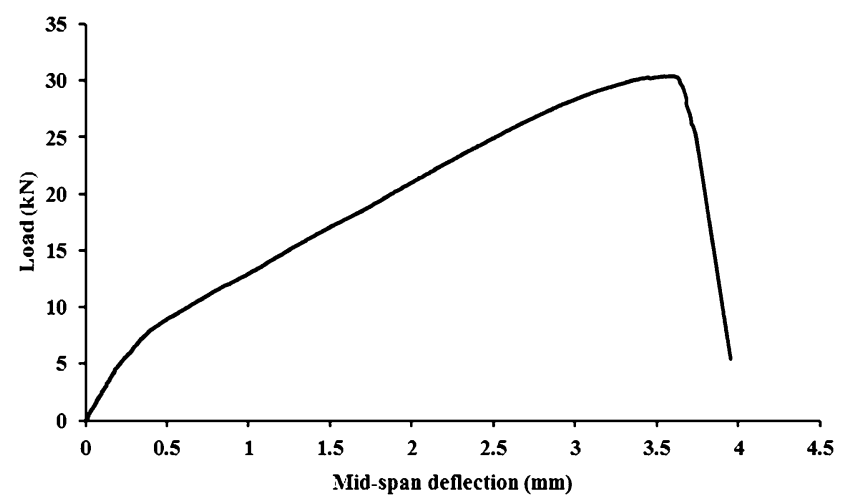

Figure 2. Load-central deflection response of the control reinforced concrete beam B1.

The crack that first appeared in the quarter span from the support started opening and propagated diagonally towards the loading point. Then a sudden failure occurred at $30.4 \mathrm{kN}$. The failure of this beam occurred in mixed shear and flexural mode (figure 3).

\subsection{Three-point flexural fatigue test of control RC beams}

Four beams (designated B2-B5) were cast following the procedure for the control beam (discussed in the Mixing and casting section). The beams were cured at ambient temperature $\left(20^{\circ} \mathrm{C}\right)$ for 28 days.

The cyclic fatigue test was carried out on three-point bending in a stiff testing frame. The central deflection was measured using a single LVDT placed underneath the beam at its mid-span. The beam was simply supported over a span of $1000 \mathrm{~mm}$. It was clamped at the supports to prevent lateral movement during the cyclic load application.

Four measurements were recorded on each beam: (1) the cyclic load range; (2) the central deflection; (3) the time and (4) the number of cycles. Tests were performed in the sinusoidal load ranges $1.5-5.5,1.5-12.5,1.5-19.5$ and $1.5-24.5 \mathrm{kN}$ corresponding, respectively, to $4.93-18.1 \%$, $4.93-41.12 \%, 4.93-64.14 \%$ and $4.93-80.59 \%$ of the static three-point failure load $(30.4 \mathrm{kN})$.

Before the cyclic load was applied, each beam was loaded and unloaded three times between 0.6 and $3 \mathrm{kN}$ in order to eliminate any slack in the machine-specimen testing system. The frequency of cyclic loading used was different for each beam according the applied load level. The test was stopped after the specimen failure or after one million cycles, whichever occurred first.

2.3a Flexural fatigue test results: Table 2 gives the number of cycles sustained by each test beam. Beam B2, which was cycled at $5 \mathrm{~Hz}$ to $18.1 \%$ of the static three-point failure load, sustained one million cycles without failure (not even minute cracks were noticed on the tension surface of this specimen). Beam B3, which was cycled at $4 \mathrm{~Hz}$ to $41.12 \%$ of the static three-point failure load, also sustained one million cycles without failure but with some minor hairline cracks on the surface. Beam B4 was cycled at $3.5 \mathrm{~Hz}$ to $64.14 \%$ and beam B5 at $2.5 \mathrm{~Hz}$ to $80.59 \%$. The reason for decreasing the frequency as the upper cyclic load level increased was to avoid any play in the machine-specimen testing system and to minimise inertial effects. The failure mode crack patterns are shown in figures 4-7.

Beam B4 with the upper cyclic load level at $64.14 \%$ of the static flexural strength sustained 596136 cycles and failed by the splitting of the steel rebar (figure 6). Calculations showed that at this load level the stress in the steel rebar was $379.63 \mathrm{MPa}$. The stress ratio used in this test was $4.93 / 64.14=0.077$ and the stress range applied to the steel bar was $350 \mathrm{MPa}$. The supplier's data sheet for this steel gave its fatigue life to be in excess of five million cycles in the cyclic stress range of $200 \mathrm{MPa}$ and a stress ratio of 0.2. As the actual cyclic stress range was $350 \mathrm{MPa}$, fatigue failure of the steel rebar led to the failure of the RC beam.

The maximum service level stress range for straight deformed reinforcing bars according to ACI 215-74 [28] is

$$
S_{r}=161-0.33 S_{\min }
$$

where $S_{r}$ is the stress range in MPa and $S_{\min }$ is the magnitude of the minimum stress in MPa. In this beam, this gives the maximum service level stress range to be just 151.4 MPa. In addition, Helgason and Hanson [29] performed a statistical analysis of test data from deformed bars tested under axial cyclic loading in air. They concluded that the lowest average stress range on reinforcing steel that causes fatigue failure is $165 \mathrm{MPa}$ and it is related to the fatigue life as follows:

$$
\log (N)=6.969-0.0055 \sigma_{r}
$$

where $N$ is number of cycles to failure and $\sigma_{r}$ is stress range applied to e steel in MPa.

Using Eq. (2), the number of cycles to failure for beam B4 loaded to $64.14 \%$ in which the reinforcement failed by fatigue works out to be 110662 cycles, which is lower than the number of cycles sustained by the beam (596136, table 2). This is a result of the fact that the fatigue life of the steel rebar embedded in concrete will exceed that measured in air in the same stress range. The reason is as follows. At the locations of the flexural cracks in the $\mathrm{RC}$

Table 2. Number of cycles sustained by RC beams B2-B5 $\left(1200 \times 150 \times 100 \mathrm{~mm}^{3}\right)$.

\begin{tabular}{lcccc}
\hline Beam & $\begin{array}{c}\text { Load amplitude } \\
\text { range }(\%)\end{array}$ & $\begin{array}{c}\text { Stress } \\
\text { ratio }\end{array}$ & $\begin{array}{c}\text { Load amplitude } \\
\text { range }(\mathrm{kN})\end{array}$ & $\begin{array}{c}\text { Fatigue life } \\
\text { (cycles) }\end{array}$ \\
\hline B2 & $4.93-18.10$ & 0.272 & $1.5-5.5$ & $>1000000$ \\
B3 & $4.93-41.12$ & 0.120 & $1.5-12.5$ & $>1000000$ \\
B4 & $4.93-64.14$ & 0.077 & $1.5-19.5$ & 596136 \\
B5 & $4.93-80.59$ & 0.061 & $1.5-24.5$ & 11458 \\
\hline
\end{tabular}




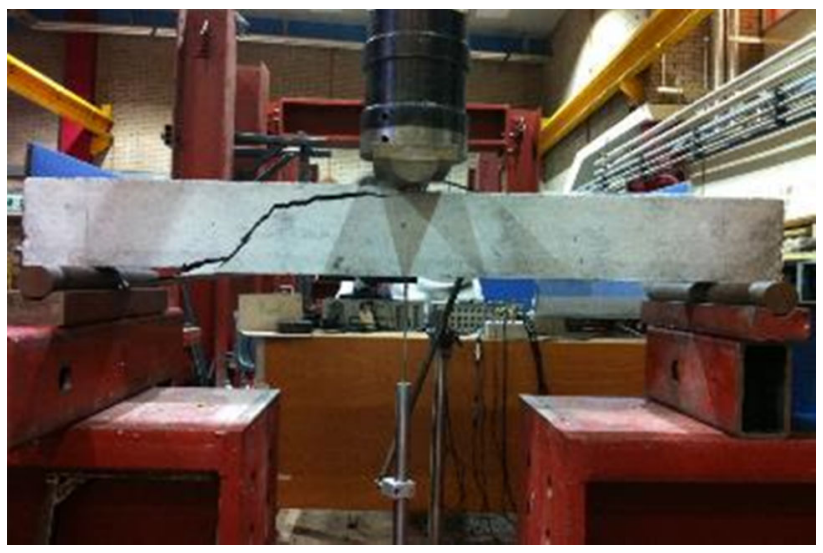

Figure 3. Failure mode of the control RC beam B1.

beam the steel rebar experiences local stress concentrations. If the defect in the embedded steel rebar from which the fatigue crack initiates coincides with one of these locations, then the fatigue life of the bar will be that measured in air. However, this is highly unlikely. Therefore, the fatigue life of a bar embedded in concrete will exceed that measured in air.

For beam B5 loaded at $80.59 \%$ the stress in the steel rebar was $477 \mathrm{MPa}$ and the stress ratio used in this test was $4.93 / 80.59=0.061$ in the stress range $447.8 \mathrm{MPa}$. The number of cycles until fatigue failure of rebar will be 32397 cycles according to Eq. (2). However, the failure of this beam occurred in the shear-flexural mode after just 11458 cycles (table 2 and figure 7), i.e., well before the fatigue failure of rebar. Even so, it is important to ensure that the reinforcing steel is not stressed beyond its fatigue endurance limit, calculated as per Eq. (1) or (2).

2.3b Compliance of fatigue test beams: The compliance of fatigue test beams B2-B5 was calculated from their recorded load-displacement curves. Under cyclic loading the compliance can increase with time, if the material sustains internal or surface damage, e.g., micro-cracking. If there is no damage then the compliance should remain constant.

Figures 8 and 9 show the variation of the compliance of beams B2-B5 with the number of cycles.

It is clear from figure 8 that the compliance of the test beams B2 and B3 remained essentially constant up to $1,000,000$ cycles, attesting to a lack of damage growth under cycling, and hence to no fatigue failure.

The compliance of beams B4 (figure 8) and B5 (figure 9) increases slowly in the beginning as the number of cycles increases before suddenly tending to infinity at failure, attesting to a brittle kind of fatigue failure.

\section{Retrofitting RC beams}

Four RC beams (B6-B9) were cast $(1200 \times$ $150 \times 100 \mathrm{~mm}^{3}$ ) using the same mix quantities and procedure as described earlier for control beams. They were retrofitted with the UHPFRC strips. One of these beams (B6) was tested under static three-point bending and used as a control beam for the other three beams (B7-B9), which were tested in different three-point bend cyclic load ranges.

\subsection{UHPFRC strips}

The UHPFRC strips with dimensions $1030 \times 100$ $\times 35 \mathrm{~mm}^{3}$ were cast in a larger steel mould partitioned for two strips. Then, after $24 \mathrm{~h}$, they were demoulded and cured in a heated water tank for 9 days (for details, see Al-Azzawi and Karihaloo [25]).

\subsection{Preparation of concrete surfaces}

To ensure good bond between the beam and the strip, the contacting surfaces were cleaned of any debris and

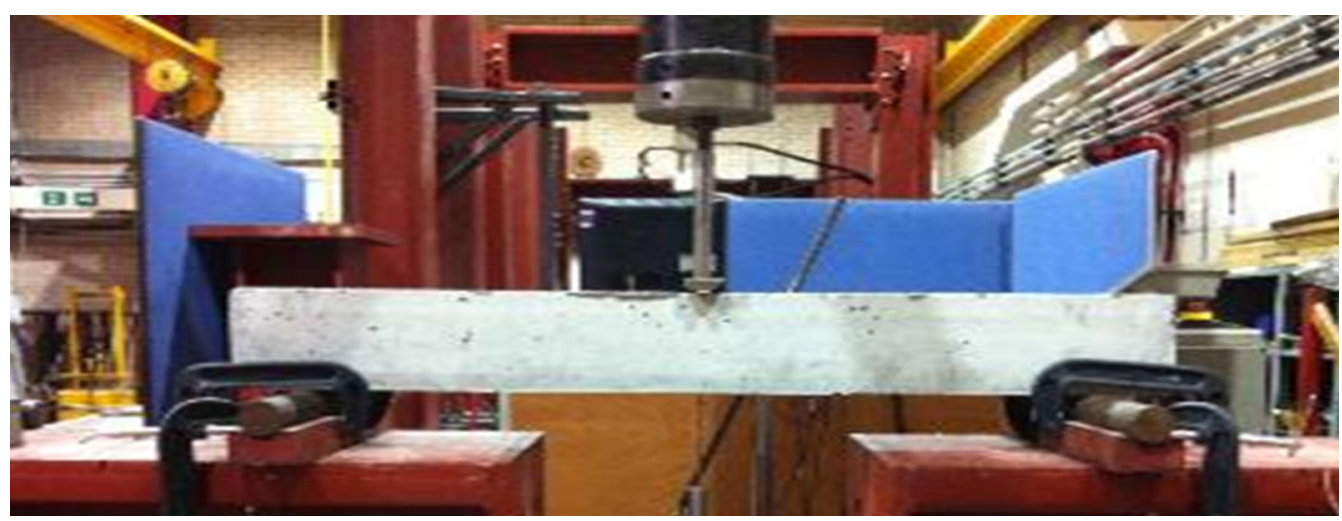

Figure 4. Beam B2 sustained 1000000 cycles without any noticeable cracks. 


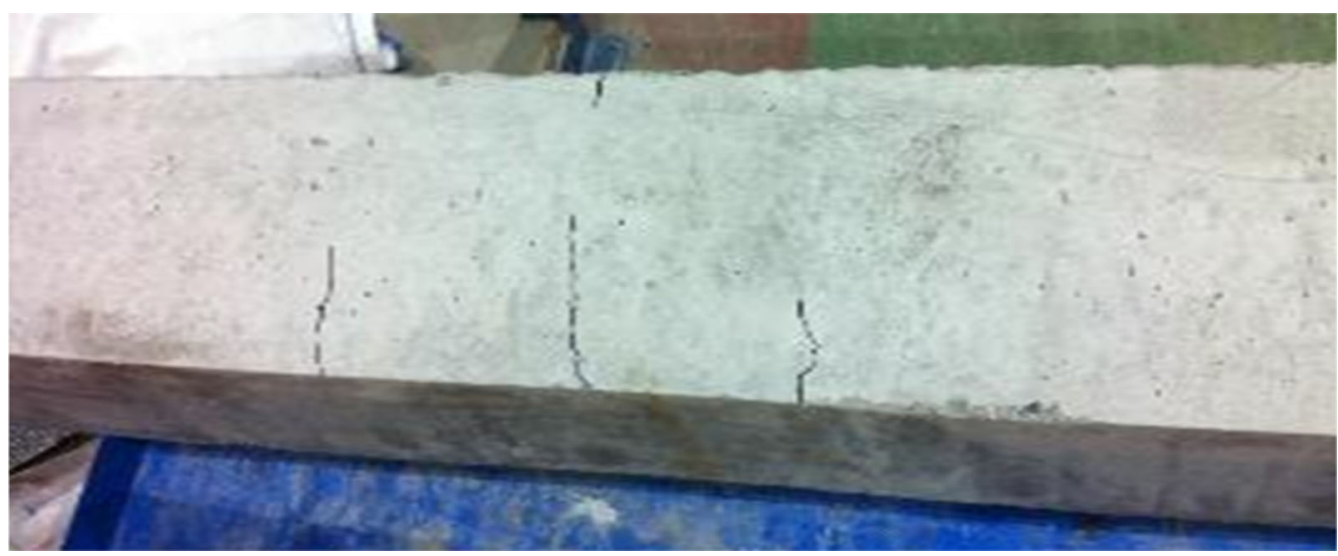

Figure 5. Beam B3 sustained 1000000 cycles with some minor cracks.

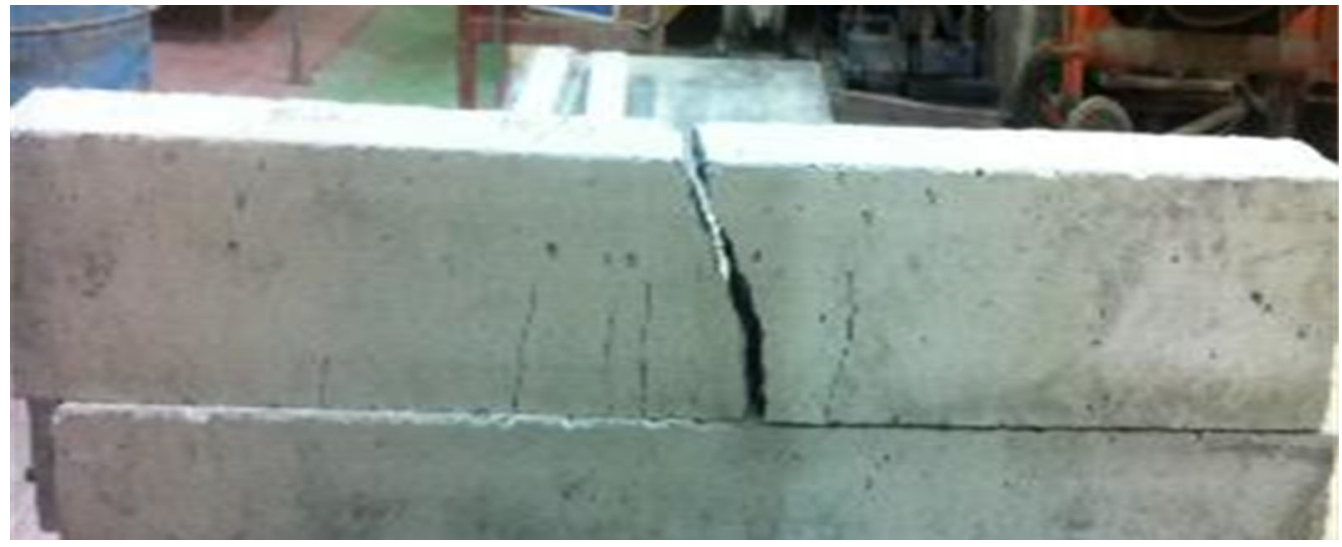

Figure 6. Beam B4 sustained 596136 cycles and failed due to rebar fatigue.

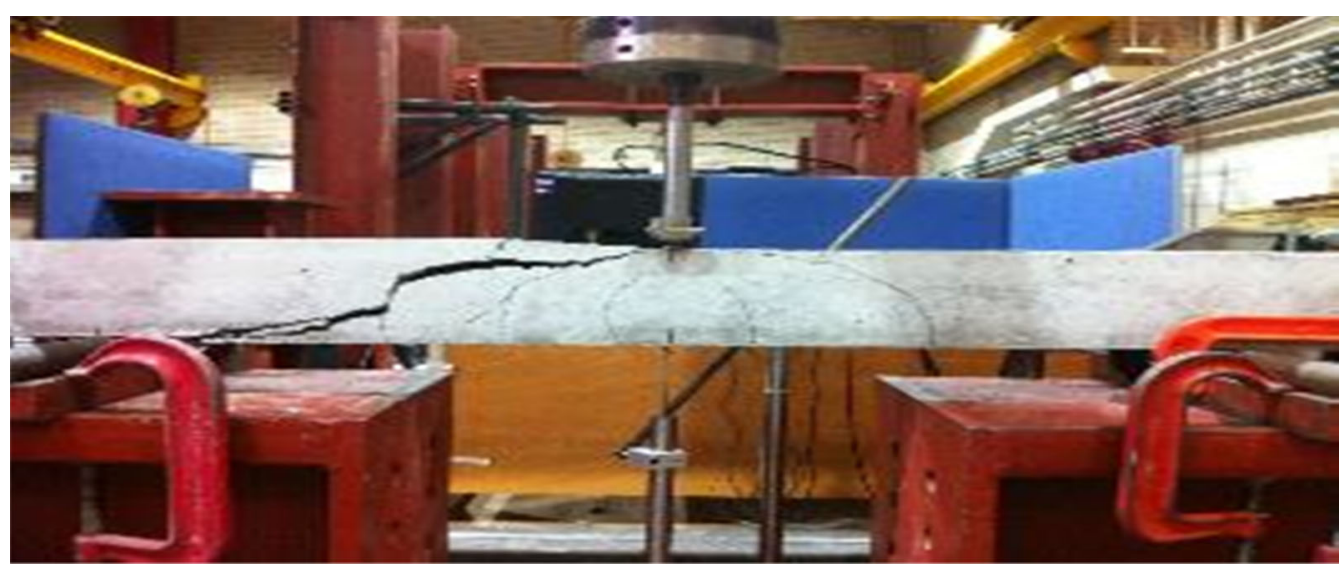

Figure 7. Beam B5 sustained 11458 cycles and failed in flexural-shear mode. 


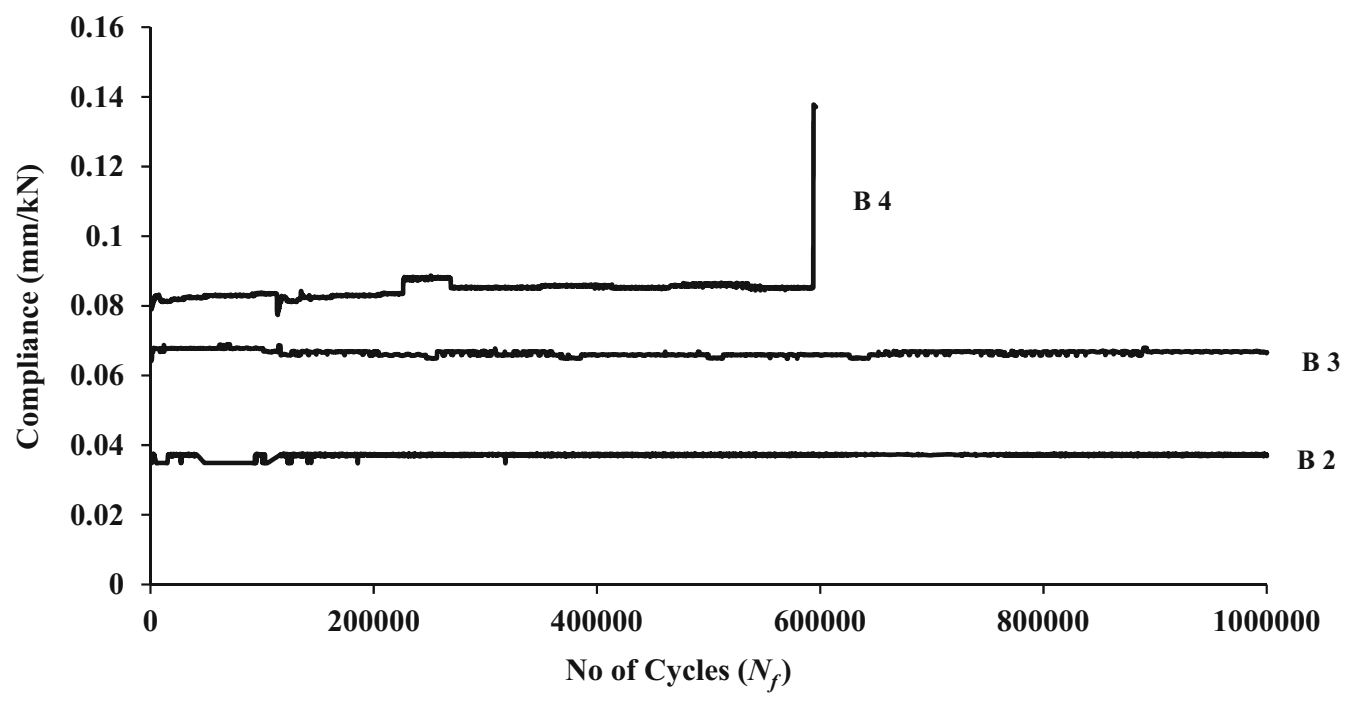

Figure 8. Compliance of RC beams B2-B4 during the ascending part of the load cycle.

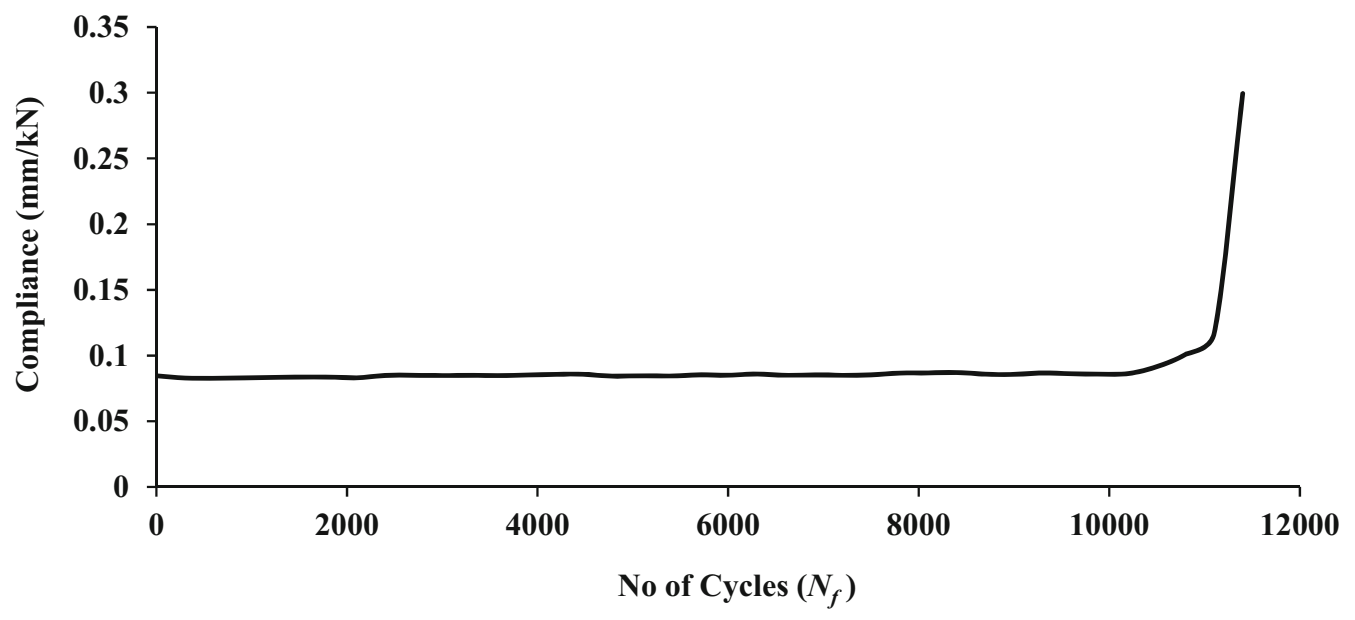

Figure 9. Compliance of RC beam B5 during the ascending part of the load cycle.

roughened using an angle grinder to create a grid of diagonal grooves $(2 \mathrm{~mm}$ deep at a spacing of $50 \mathrm{~mm}$ ) (figure 10).

\subsection{Adhesive bonding of strips}

The strips were bonded to the prepared tension surface of the beams with a commercial thixotropic epoxy. The two parts of the adhesive were thoroughly mixed and applied to the tension side of the beam with a serrated trowel to a uniform thickness of $3 \mathrm{~mm}$. The strip was then placed on the adhesive and evenly pressed. To ensure good adhesion, pressure was applied by placing weights along the strip during the hardening of the adhesive for $24 \mathrm{~h}$
(G-clamps can be used instead of weights). It should be mentioned that Alaee and Karihaloo [22] and Farhat et al. [24] have tried an alternative method of retrofitting with the original CARDIFRC. Instead of bonding precast strips they placed fresh CARDIFRC on the prepared surface for which it was necessary to use formwork and to await the curing of the wet mix. They found that the static ultimate capacity of the retrofitted beams was practically unaffected by the method of retrofitting. Either of these two methods may therefore be used depending upon the application and access to the RC member being retrofitted. The method of retrofitting using fresh self-compacting UHPFRC may for example be more appropriate when there is restricted access to the $\mathrm{RC}$ member. The self-compacting nature of this 


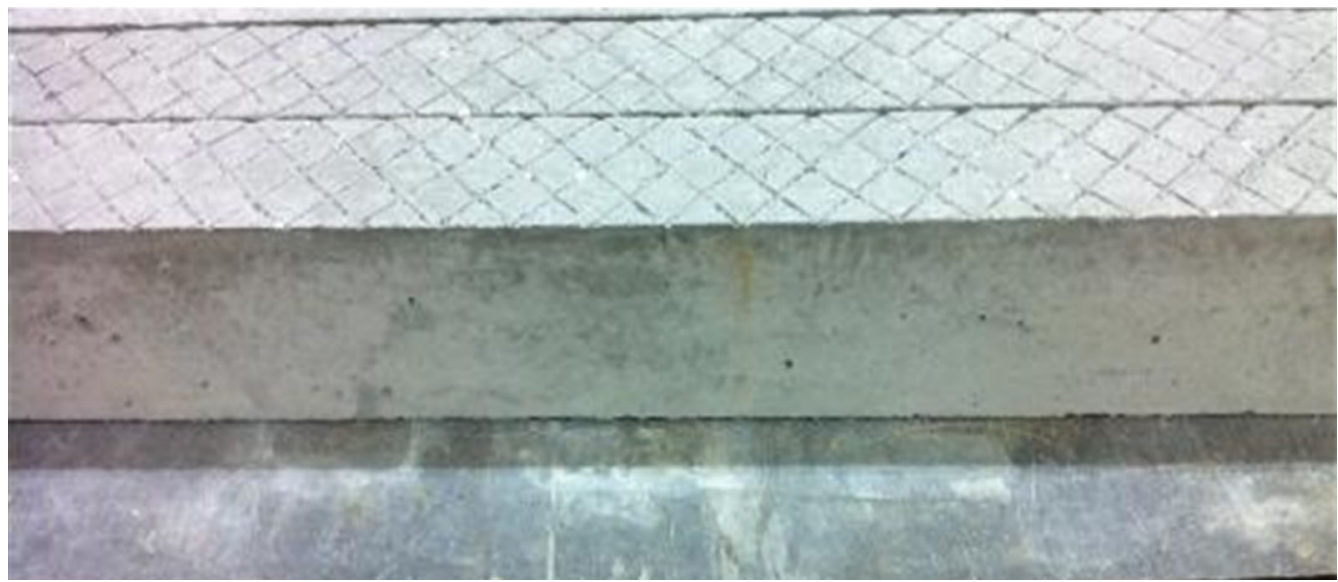

Figure 10. A grid of diagonal grooves to roughen the surface for bonding.

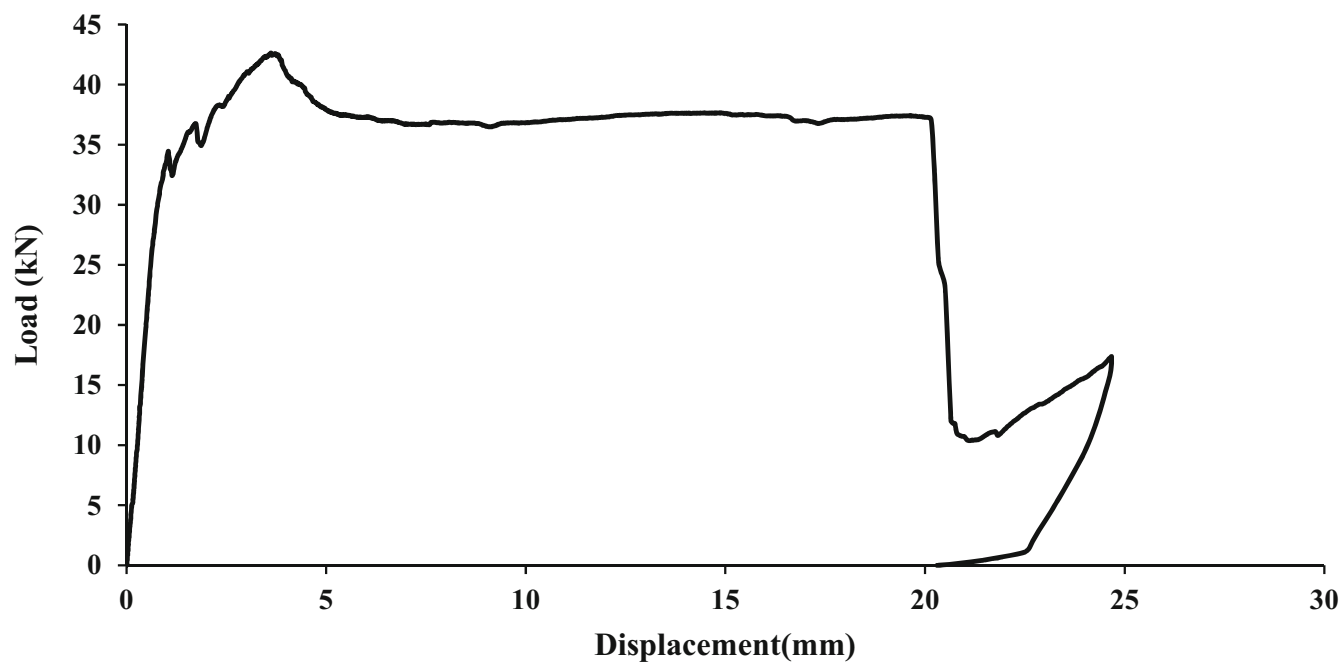

Figure 11. Static load-central deflection response of the retrofitted reinforced concrete beam B6.

UHPFRC makes it particularly suitable for use in tight spaces because there is no need for external vibratory compaction.

\subsection{Three-point static flexural test of retrofitted beam}

One of the retrofitted RC beams (B6) was tested under three-point static bend over a clear span of $1000 \mathrm{~mm}$ following the same procedure as that for the control bean without retrofitting. Figure 11 shows the load-central deflection response of this retrofitted beam.

The failure mode of this beam, shown in figure 12, is essentially flexural. The maximum load carried by this beam was $42.63 \mathrm{kN}$. This means that retrofitting by a single $35 \mathrm{~mm}$ thick strip of UHPFRC on the tension face has

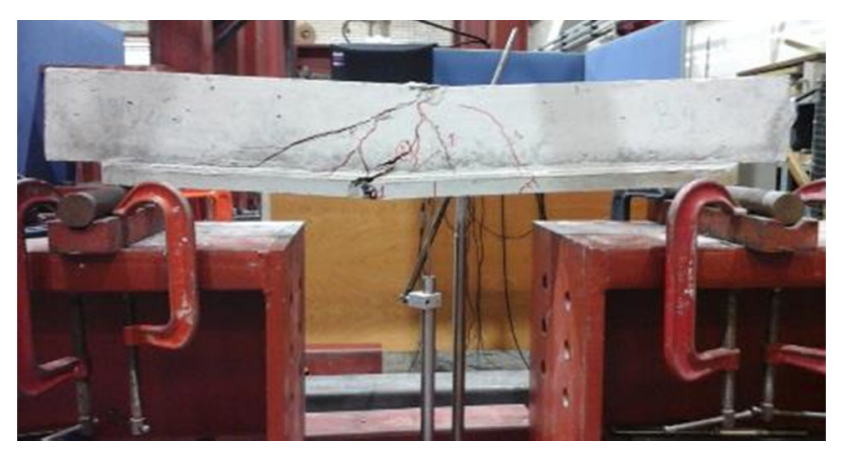

Figure 12. Flexural cracking in beam B6 retrofitted with $35 \mathrm{~mm}$ thick strip.

increased the load carrying capacity by approximately $40 \%$ (from 30.4 to $42.63 \mathrm{kN}$ ) and led to a failure mode transition from nearly brittle to ductile (cf. figures 3 and 12). 
Table 3. Number of cycles sustained by retrofitted RC beams B7-B9 $\left(1200 \times 150 \times 100 \mathrm{~mm}^{3}\right)$.

\begin{tabular}{lcccc}
\hline Beam & $\begin{array}{c}\text { Load amplitude } \\
\text { range }(\%)\end{array}$ & $\begin{array}{c}\text { Stress } \\
\text { ratio }\end{array}$ & $\begin{array}{c}\text { Load amplitude } \\
\text { range }(\mathrm{kN})\end{array}$ & $\begin{array}{c}\text { Fatigue life } \\
\text { (cycles) }\end{array}$ \\
\hline B7 & $3.52-46.91$ & 0.075 & $1.5-20$ & $>1000000$ \\
B8 & $3.52-60.99$ & 0.058 & $1.5-26$ & $>1000000$ \\
B9 & $3.52-82.10$ & 0.043 & $1.5-35$ & 32100 \\
\hline
\end{tabular}

\subsection{Three-point flexural fatigue test of retrofitted concrete beams}

3.5a Flexural fatigue test results: The remaining three retrofitted beams (B7-B9) were subjected to cyclic three-point bending in a DARTEC $250 \mathrm{kN}$ dynamic-static actuator. The central deflection was measured using a single LVDT placed underneath the beam at its mid-span. The beam was simply supported over a span of $1000 \mathrm{~mm}$. To prevent the beam from moving laterally during the cyclic load application, the base plates of the simple roller supports were clamped (figure 12).

The actuator was connected to a DARTEC 9600 Digital Feedback Controller. Four measurements were recorded on each beam: (1) the cyclic load; (2) the central deflection; (3) the time and (4) the number of cycles.

The sinusoidal load ranges were 1.5-20, 1.5-26 and $1.5-35 \mathrm{kN}$, corresponding, respectively, to $3.52-46.91 \%$, $3.52-60.99 \%$ and $3.52-82.1 \%$ of the static three-point strength. Table 3 gives the number of cycles sustained by each test specimen. The crack patterns/failure modes are shown in figures 13-15.

Beam B7, which was cycled to $46.91 \%$ of the static three-point failure load, sustained one million cycles without failure (not even minute cracks were noticed on the tension surface of this specimen, figure 13). The frequency of cyclic loading used was $5 \mathrm{~Hz}$. Beam B8, which was cycled to $60.99 \%$ of the static three-point strength, also sustained one million cycles without failure but a few hairline cracks were noticed in the middle third area (figure 14). This time the frequency of cyclic loading used was $3.5 \mathrm{~Hz}$. Beam B9 was cycled to $82.1 \%$ at a frequency of $2.5 \mathrm{~Hz}$ (figure 15). It is important to mention that beam B9, which was loaded to $82.1 \%$ of the static three-point strength, failed by fatigue of the reinforcing steel bar. An explanation will be provided later after considering the compliance of the retrofitted beam.

3.5b Compliance of fatigue test beams: Figures 16-18 show the variation in the compliance of test beams with the number of cycles. The compliance of beam B7 subjected to the load range $1.5-20 \mathrm{kN}$ remained practically unchanged with increasing number of cycles (figure 16), confirming that there was no damage evolution or accumulation in this beam right up to $10^{6}$ cycles (figure 13). The compliance of beam B8 subjected to the load range $1.5-26 \mathrm{kN}$ did increase slightly (figure 17) when cracks formed on the surface (figure 14), which led to the well-known tension stiffening. However, overall, this beam sustained $10^{6}$ load cycles, despite the minor damage in the form of hairline flexural cracks.

The compliance of beam B9 subjected to the load range $1.5-35 \mathrm{kN}$ increased noticeably after just 5000 cycles (figure 18) due to the formation of a major flexural crack in the UHPFRC strip (see figure 15). As a result, the contribution of the strip to the tensile load carrying capacity is reduced and that of the reinforcing steel bar is increased. The reinforcing bar is therefore subjected to an elevated cyclic stress range of approximately $268.46 \mathrm{MPa}$ (see "Appendix A"). This stress range is much higher than the allowable limit recommended by the supplier's data sheet (cyclic stress range $200 \mathrm{MPa}$ for a fatigue life in excess of five million cycles), thus leading to the fatigue failure of the reinforcing bar (figure 15).

As the minimum stress used was the same for all tested beams, the maximum service level stress range should be

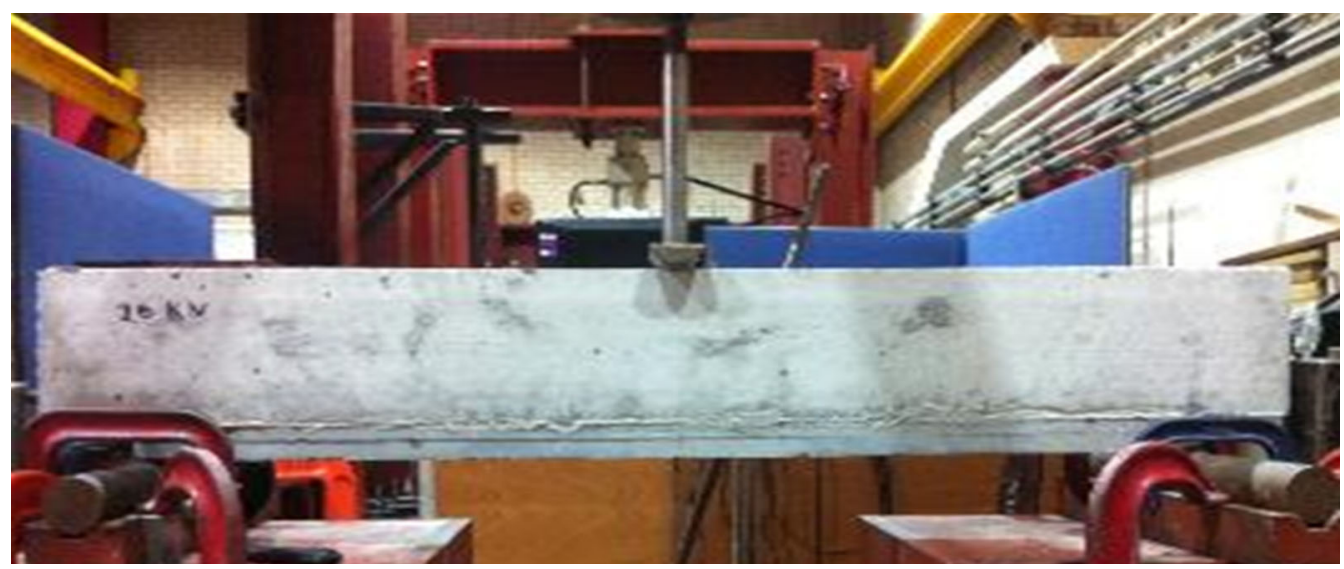

Figure 13. Beam B7 sustained 1000000 cycles without any noticeable cracks (maximum cyclic load level $46.91 \%$ ). 


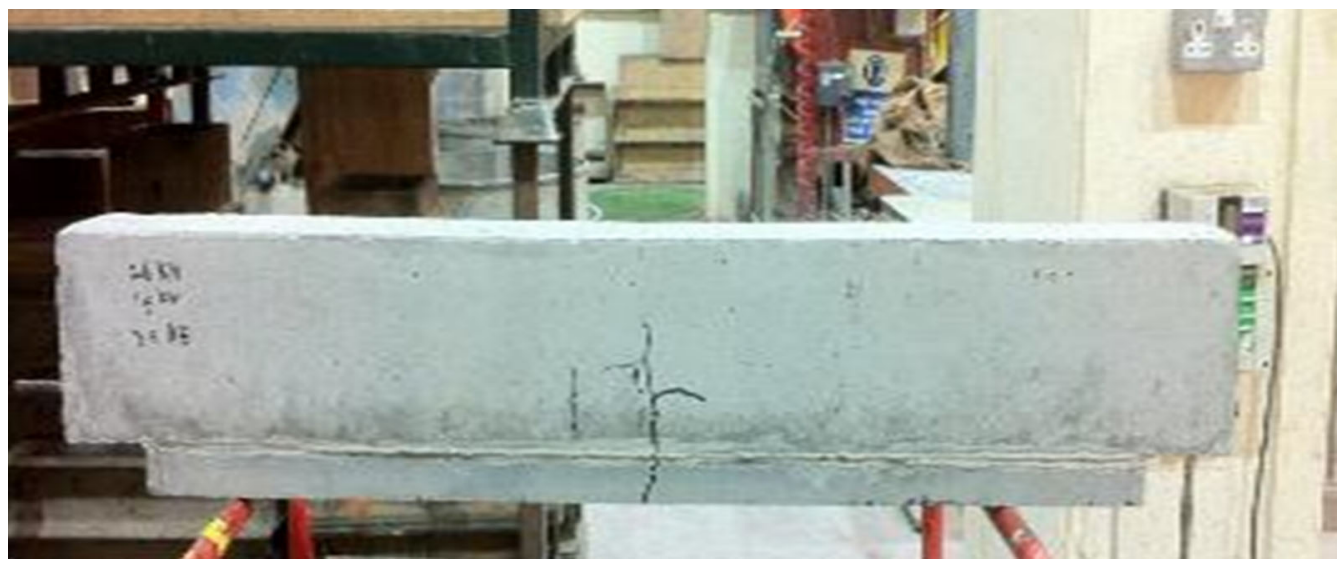

Figure 14. Beam B8 sustained 1000000 cycles with some cracks (maximum cyclic load level 60.99\%).

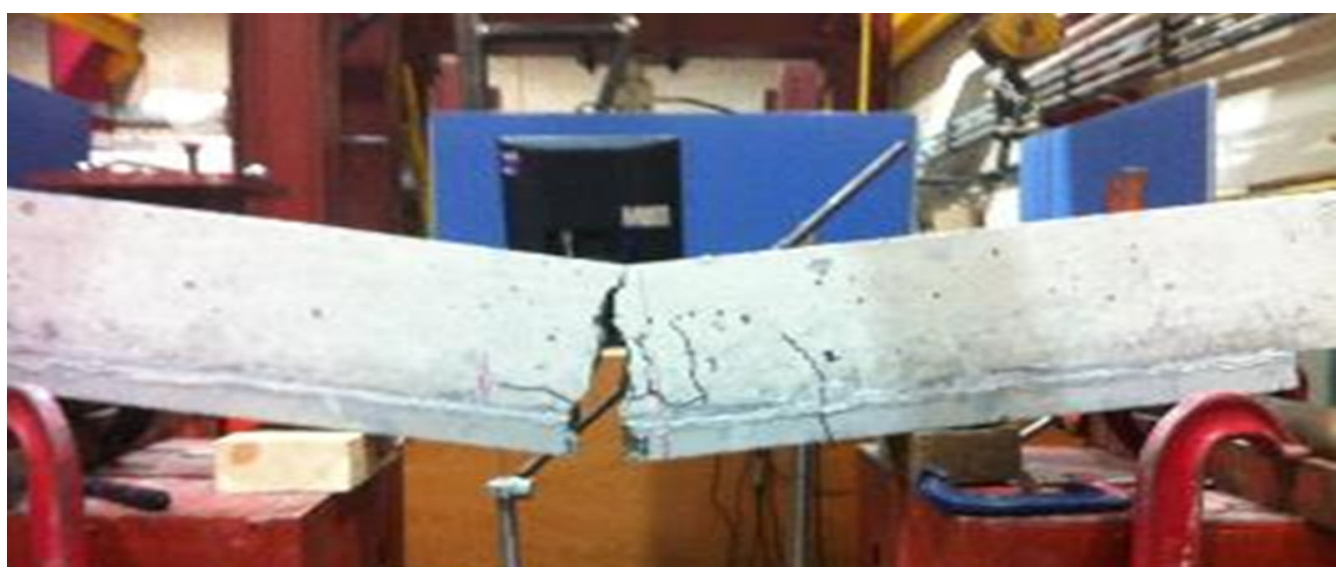

Figure 15. Beam B9 sustained 32100 cycles and failed by rebar fatigue (maximum cyclic load level $82.1 \%$ ).

just 151.4 MPa according to ACI 215-74 [28] (Eq. (1)), which is well below the actual stress range (268.46 MPa) in the test beam subjected to maximum load amplitude of $35 \mathrm{kN}$. Additional guidance is provided by Papakonstantinou et al [30], who give a regression equation to estimate the fatigue life of beams retrofitted with GFRP sheets:

$$
\log (N)=6.677-0.00613 \sigma_{r}
$$

From Eq. (3) the number of cycles to failure for beam B9 cycled up to $82.1 \%$ will be 107475 cycles, whereas the beam sustained only 32100 cycles. This is no doubt due to the fact that GPRP makes a much larger contribution to the tensile load carrying capacity than the UHPFRC material used in this work for retrofitting.

It can be concluded from this limited number of fatigue tests that the endurance limit of RC beams retrofitted with a UHPFRC strip is approximately $60 \%$ of static flexural strength, while the endurance limit of the RC beams without retrofitting, as shown earlier, is just $40 \%$ of static flexural strength. It should be noted that all test beams (i.e., beams with or without retrofitting) were subjected to cyclic loading with a non-zero mean stress. What is more, the mean stress increased (the stress ratio decreased) with increasing maximum load amplitude, as the minimum load amplitude was held constant. Thus, the fatigue endurance limit under zero mean stress cyclic loading would be higher than that stated earlier.

\section{Estimation of the number of cycles to failure}

The choice of the frequency was made taking into consideration the time required for the test specimen to reach one million cycles. The test was stopped if the specimen sustained one million cycles without failure. This does not however mean that the fatigue life of the material is just one million cycles. 


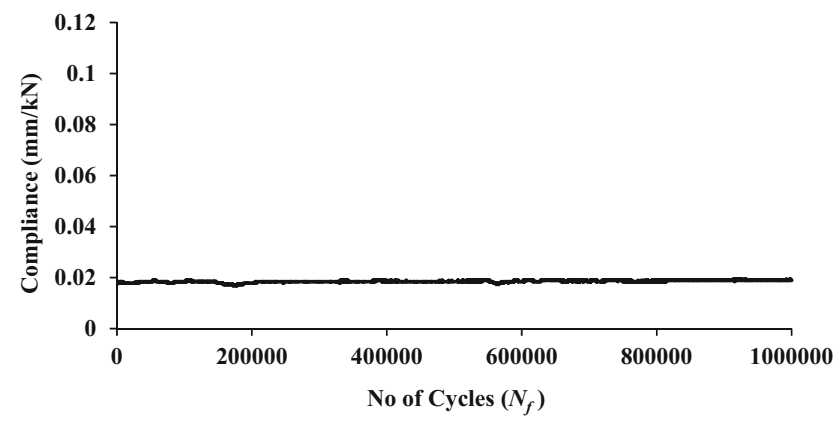

Figure 16. Compliance of retrofitted RC beam B7 during the ascending part of the load cycle.

In order to have some idea of what the fatigue life in a given cyclic load range is, it may for instance be assumed that the material is deemed to have failed when its compliance has doubled, i.e., its stiffness has reduced to half its pre-loading level.

For this, we can use the variation in the compliance of the specimens to predict the fatigue life for each specimen using the initial compliance $c_{i}$ and the rate of change of the compliance with the number of cycles (figures 8, 9 and 1618):

$$
\int_{c_{i}}^{2 c_{i}} d c=R \int_{0}^{N_{p f}} d N
$$

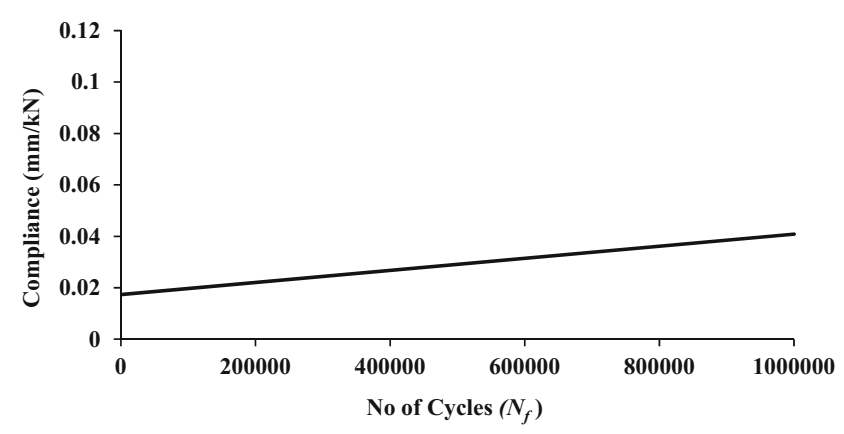

Figure 17. Compliance of retrofitted $\mathrm{RC}$ beam B8 during the ascending part of the load cycle.

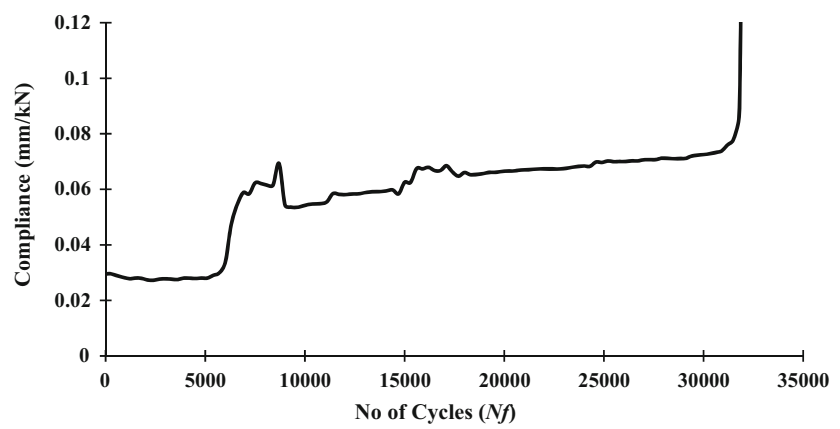

Figure 18. Compliance of retrofitted RC beam B9 during the ascending part of the load cycle.
Table 4. Predicted number of cycles with load amplitude range for $\mathrm{RC}$ beams without retrofitting.

\begin{tabular}{lccc}
\hline Beam & $\begin{array}{c}\text { Stress range } \\
(\%)\end{array}$ & $\begin{array}{c}\text { Load amplitude range } \\
(\mathrm{kN})\end{array}$ & No of cycles \\
\hline B2 & $4.93-18.10$ & $1.5-5.5$ & $131 \times 10^{6}$ \\
B3 & $4.93-41.12$ & $1.5-12.5$ & $25.735 \times 10^{6}$ \\
B4 & $4.93-64.14$ & $1.5-19.5$ & 593700 \\
B5 & $4.93-80.59$ & $1.5-24.5$ & 11400 \\
\hline
\end{tabular}

Table 5. Predicted number of cycles with load amplitude range for retrofitted RC beams.

\begin{tabular}{lccc}
\hline Beam & $\begin{array}{c}\text { Stress range } \\
(\%)\end{array}$ & $\begin{array}{c}\text { Load amplitude range } \\
(\mathrm{kN})\end{array}$ & No of cycles \\
\hline B7 & $3.52-46.91$ & $1.5-20$ & $10.637 \times 10^{6}$ \\
B8 & $3.52-60.99$ & $1.5-26$ & $10^{6}$ \\
B9 & $3.52-82.10$ & $1.5-35$ & 32100 \\
\hline
\end{tabular}

Then the predicted number of cycles to failure is

$$
N_{p f}=\frac{c_{i}}{R}
$$

where $c_{i}$ is the initial compliance, $R$ is the rate of change of compliance per cycle and $N_{p f}$ is the predicted number of cycles to failure (i.e., when the compliance has doubled).

The predicted number of cycles with the applied stress range for each specimen is tabulated in tables 4 and 5 for $\mathrm{RC}$ beams without and with retrofitting, respectively.

Table 4 shows that the predicted number of cycles to failure for $\mathrm{RC}$ beams without retrofitting is well above that recorded during the test, which was terminated at one million cycles up to the maximum load amplitude of $12.5 \mathrm{kN}$, i.e., approximately $40 \%$ of the ultimate static three-point flexural load of $30 \mathrm{kN}$.

Likewise, table 5 shows that the predicted number of cycles to failure for retrofitted $\mathrm{RC}$ beams is also well above that recorded during the test up to the maximum load amplitude of $20 \mathrm{kN}$, i.e., approximately $47 \%$ of the ultimate static flexural load of $42 \mathrm{kN}$. Even at the maximum load of $26 \mathrm{kN}$, i.e., $60.99 \%$ of ultimate static flexural load, the number of cycles to failure is one million, i.e., the same number of cycles as this retrofitted beam sustained during testing.

\section{Discussion}

Retrofitting with a $35 \mathrm{~mm}$ thick UHPFRC strip increases the ultimate static three-point flexural load from 30 to $42 \mathrm{kN}$, i.e., by about $40 \%$. The improvement in the endurance limit is from $40 \%$ to $60 \%$ of the static three-point flexural strength. In terms of load, this corresponds to an increase from 12.5 to 
$26 \mathrm{kN}$ in the upper cyclic load amplitude (the lower limit is $1.5 \mathrm{kN}$ in both cases), i.e., an increase of more than $116 \%$.

This increase in the endurance limit of retrofitted $\mathrm{RC}$ beam is for cyclic loading with a non-zero mean stress. What is more, the mean stress increased (the stress ratio decreased) with increasing maximum load amplitude, as the minimum load amplitude was held constant. Thus, the fatigue endurance limit under zero mean stress cyclic loading would be much higher than that stated earlier. This follows from investigations on the flexural fatigue of UHPFRC by Al-Azzawi and Karihaloo [26].

In choosing the upper cyclic load amplitude it is important to bear in mind the fatigue endurance limit of the reinforcing steel. For example, for the reinforcing steel used in the current research the supplier's data sheet stated that the cyclic stress range is only $200 \mathrm{MPa}$ at a stress ratio of 0.2 for bars less than $16 \mathrm{~mm}$ in diameter. However, as the smallest stress ratio in our test on $\mathrm{RC}$ beam without retrofitting that sustained $10^{6}$ cycles was $4.93 / 41.12=0.12$ and on retrofitted beam it was 3.52/ $60.99=0.058$, the allowable cyclic stress range on the reinforcing steel would be above $200 \mathrm{MPa}$.

\section{Conclusions}

- Retrofitting with a UHPFRC strip is far more effective under cyclic than static loading. The increase in the fatigue endurance limit is far more than the increase in the static ultimate capacity.

- As the tests were terminated at one million cycles, an indication of the expected fatigue life in a given cyclic load range with non-zero mean stress can be obtained from the recorded variation in the compliance, by assuming, for instance, that the beam is deemed to have failed when its compliance under cyclic loading has doubled.

- Finally, it should be mentioned that no attempt was made to study the effect of structural size or shear reinforcement on the endurance limit. This needs further investigation.

\section{Appendix A}

Applying the traditional transformed area methodology to the retrofitted $\mathrm{RC}$ beam subjected to the three-point bend cyclic load range $1.5-35 \mathrm{kN}$, it is found that the neutral axis lies at $91.3 \mathrm{~mm}$ from the extreme compression fibre and the second moment of area of the cross section is $56.08 \times 10^{6} \mathrm{~mm}^{4}$. Accordingly, at the lower load limit of $1.5 \mathrm{kN}$, the stresses in concrete extreme fibre, steel reinforcing bar and the extreme fibre of the retrofitting UHPFRC strip are $0.61,1.47$ and $0.75 \mathrm{MPa}$, respectively.

Assuming that the UHPFRC strip had reached its tensile strength of 12.02 MPa (Al-Azzawi and Karihaloo [25]) but not cracked at the upper load limit of $35 \mathrm{kN}$, the corresponding stresses in concrete would be $14.25 \mathrm{MPa}$ and in the steel bar, 203.1 MPa. The cyclic stress range in the steel bar would be $201.63 \mathrm{MPa}$ at a stress ratio of $1.47 /$ $203.1=0.0072$. This cyclic stress range is very close to the allowable limit in the supplier's data sheet (cyclic stress range $200 \mathrm{MPa}$ and a stress ratio of 0.2 for a fatigue life in excess of five million cycles).

However, as noted in the text a major flexural crack formed in the UHPFRC strip in this cyclic load range after approximately 5000 cycles. The reduced tension carrying capacity of the UHPFRC strip can be estimated from its known stress-crack opening relation (Al-Azzawi and Karihaloo [25]), figure 19). At a crack opening of, say, $1 \mathrm{~mm}$, the tensile strength of UHPFRC reduces from 12.02 to $9.86 \mathrm{MPa}$, so that its contribution to the tensile capacity of the retrofitted beam reduces from 42.07 to $34.5 \mathrm{kN}$ and that of the reinforcing steel must increase to $30.53 \mathrm{kN}$, from $22.97 \mathrm{kN}$ (figure 20). As a result the stress in steel increases to $269.93 \mathrm{MPa}$. The cyclic stress range in the steel bar is $268.46 \mathrm{MPa}$ at a stress ratio of $1.47 / 269.93=0.0054$, which is well in excess of the supplier's recommended stress range of $200 \mathrm{MPa}$ for this steel.

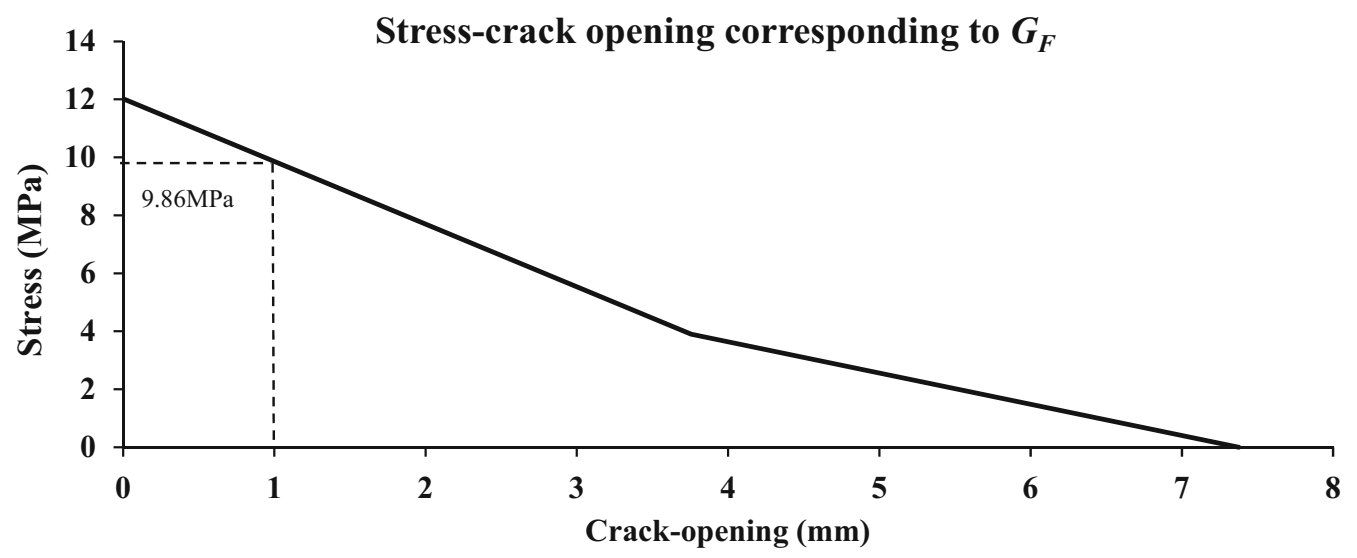

Figure 19. Tensile stress-crack opening relation of UHPFRC corresponding to its size-independent specific fracture energy. 


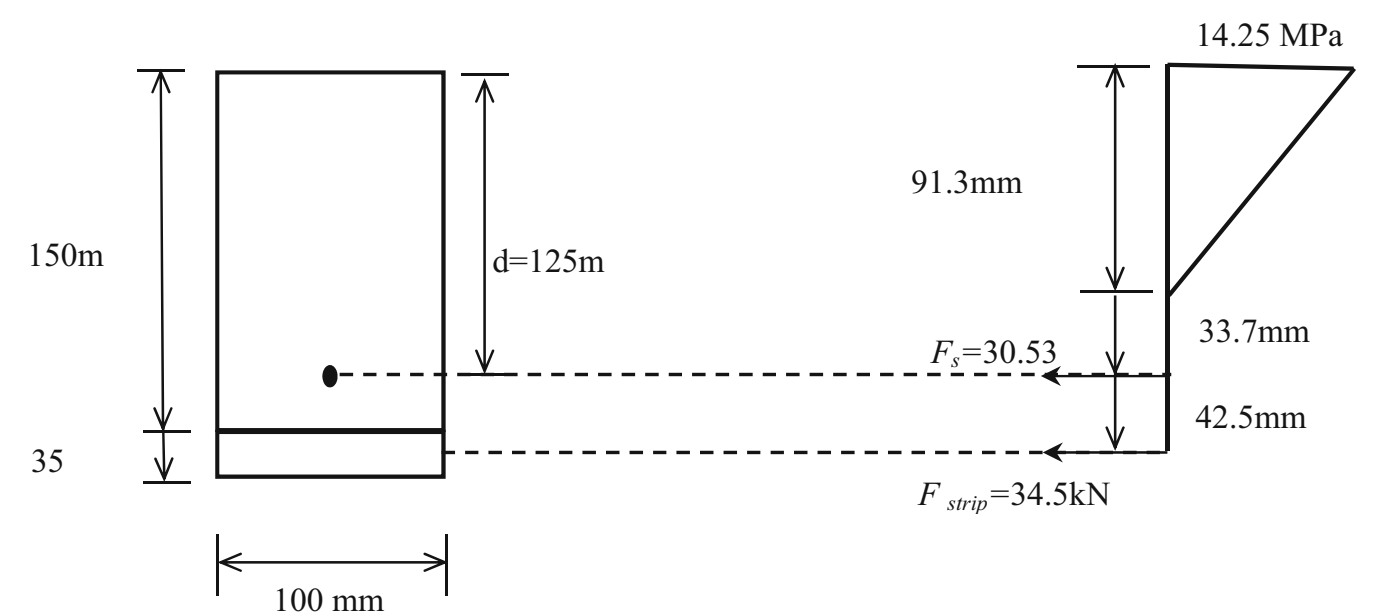

Beam with UHPFRC strip $\quad$ Force distribution in the section

Figure 20. Contributions of retrofitting strip after it has cracked and of steel bar to tension under a mid-span load of $35 \mathrm{kN}$.

\section{References}

[1] RILEM 1984 Long term random dynamic loading of concrete structures. Mater. Struct. 17: 1-27

[2] Derkowski W and Zych T 2004 Modern composite materials for strengthening of building structures (in Polish). Czasopismo Tech. 14-B: 15-25

[3] Jones R, Swamy R N and Charif A 1988 Plate separation and anchorage of reinforced concrete beams strengthened by epoxy-bonded steel plates. Struct. Eng. 66(5): 85-94

[4] Nanni A 1995 Concrete repair with externally bonded FRP reinforcement: examples from Japan. Concr. Int. 97: 22-26

[5] Sen R, Mullins G, Shahawy M and Spain J 2000 Durability of CFRP-epoxy-concrete bond. Composites in the transportation industry. In: Proceedings of the ACUN-2 International Composite Conference, University of South Wales, Sydney, Australia, pp. 259-265

[6] Heffernan P J and Erki M A 2004 Fatigue behavior of reinforced concrete beams strengthened with carbon fiber reinforced plastic laminates. J. Compos. Constr. 8(2): 132-140, https://doi.org/10.1061/(asce)1090-0268

[7] El-Saikaly G, Chaallal O and Godat A 2014 Fatigue behaviour of RC beams retrofitted in shear with externally bonded CFRP sheets. In: Proceedings of the 7th International Conference on FRP Composites in Civil Engineering, CICE, Vancouver, Canada

[8] Buyukozturk O and Hearing B 1998 Failure behavior of precracked concrete beams retrofitted with FRP. J. Compos. Constr. 2(3): 138-144, https://doi.org/10.1061/(asce)10900268

[9] Bakis C E, Bank L C, Brown V L, Cosenza E, Davalos J F, Lesko J J, Machida A, Rizkalla S H and Triantaillou T C 2002 Fiber-reinforced polymer composites for construction state-of-the-art review. J. Compos. Constr. 6(2): 73-78, https://doi.org/10.1061/(ASCE)1090-0268

[10] Karbhari V M 1998 Material and design considerations in FRP rehabilitation of concrete structures. In: Proceedings of
FRAMCOS-3. Freiburg, Germany: AEDIFICATIO Publishers, pp. $1805-1816$

[11] Zhen M and Chung D D L 2000 Effects of temperature and stress on the interface between concrete and its fibre-matrix composite retrofit, studies by electrical resistance measurement. Cem. Concr. Res. 30: 799-802

[12] Sharmila S and Thirugnanam G S 2013 Behavior of reinforced concrete flexural member with hybrid fibre under cyclic loading. Int. J. Sci. Environ. Technol. 2(4): 725-734

[13] Khan M I, Abbas Y M and Fares G 2017 Review of high and ultrahigh performance cementitious composites incorporating various combinations of fibres and ultrafines. J. King Saud. Univ. - Eng. Sci., https://doi.org/10.1016/j.jksues. 2017.03.006

[14] Makita T and Brühwiler E 2014 Tensile fatigue behaviour of ultra-high performance fibre reinforced concrete combined with steel rebars (R-UHPFRC). Int. J. Fatig. 59: 145-152

[15] Li X, Wang J, Bao Y and Chen G 2017 Cyclic behavior of damaged reinforced concrete columns repaired with highperformance fiber-reinforced cementitious composite. Eng. Struct. 136: 26-35

[16] Benson S D P and Karihaloo B L 2005 CARDIFRC development and mechanical properties. Part 1: development and workability. Mag. Concr. Res. 57(6): 347-352

[17] Benson S D P and Karihaloo B L 2005 CARDIRFC development and mechanical properties. Part III: uniaxial tensile response and other mechanical properties. Mag. Concr. Res. 57(8): 433-443

[18] Benson S D P, Nicolaides D and Karihaloo B L 2005 CARDIFRC - development and mechanical properties. Part II: fibre distribution. Mag. Concr. Res. 57(7): 412-432

[19] Karihaloo B L, Alaee F J and Benson S D P 2002 A new technique for retrofitting damaged concrete structures. Proc. Inst. Civ. Eng. - Struct. Build. 152(4): 309-318

[20] Karihaloo B L, Benson S D P, Didiuk P M, Fraser S A, Hamill N and Jenkins T A 2000 Retrofitting damaged RC beams with high-performance fibre-reinforced concrete. In: 
Proceedings of the 10th Annual BCA, British Cement Association, Birmingham University, pp. 153-164

[21] Alaee F J and Karihaloo B L 2003 Fracture model for flexural failure of beams retrofitted with CARDIFRC. J. Eng. Mech. 129(9): 1028-1038, https://doi.org/10.1061/ (ASCE)0733-9399

[22] Alaee F J and Karihaloo B L 2003 Retrofitting of reinforced concrete beams with CARDIFRC. J. Compos. Constr. 7(3), 174-186, https://doi.org/10.1061/(ASCE)1090-0268

[23] Farhat F A, Nicolaides D, Kanellopoulos A and Karihaloo B L 2007 High performance fibre-reinforced cementitious composite (CARDIFRC) - performance and application to retrofitting. Eng. Fract. Mech. 74: 151-167

[24] Farhat F A, Nicolaides D, Kanellopoulos A and Karihaloo B L 2010 Behavior of RC beams retrofitted with CARDIFRC after thermal cycling. J. Mater. Civ. Eng. 22(1): 21-28, https://doi.org/10.1061/(ASCE)1943-5533.0000008

[25] Al-Azzawi B S and Karihaloo B L 2017 Mechanical and fracture properties of a self-compacting version of CARDIFRC Mix II. Sadhana 42(5): 795-803, https://doi.org/10. 1007/s12046-017-0641-9
[26] Al-Azzawi B S and Karihaloo B L 2017 Flexural fatigue behaviour of a self-compacting ultra-high performance fiberreinforced concrete. ASCE J. Mater. Civ. Eng. 29(11): 04017210, https://doi.org/10.1061/(asce)mt.1943-5533. 0002051

[27] Farshid J A 2002 Retrofitting of concrete structures using high performance fibre reinforced cementitious composite (HPFRCC). PhD Thesis, Cardiff University, UK

[28] ACI 215R-74 1992 Considerations for design of concrete structures subjected to fatigue loading. ACI Committee Report, American Concrete Institute

[29] Halgason T and Hanson J M 1974 Investigation of design factors affecting fatigue strength of reinforcing bars-statistical analysis. In: Proceedings of the Abeles Symposium on Fatigue of Concrete, SP-41, ACI Detroit, pp. 107-138

[30] Papakonstantinou C G, Petrou M F and Kent A H 2001 Fatigue behavior of RC beams strengthened with GFRP sheets. J. Compos. Constr. 5(4): 246-253, https://doi.org/10. 1061/(asce)1090-0268/01/0004-0246-02535 